\title{
Is it bowel-associated dermatosis- arthritis syndrome induced by small intestinal bacteria overgrowth?
}

\author{
Hongjun Zhao', Lijuan Zhao', Wei Shi², Hui Luo', Liping Duan', Yunhui You', Yisha Li" and Xiaoxia Zuo'
}

\begin{abstract}
Introduction: Bowel-associated dermatosis-arthritis syndrome is rare systemic diseases characterized by a prodrome of fever, chills, and influenza-like symptoms with subsequent skin eruptions, myalgias, and polyarthralgias. It is reported to be occurred in Intestinal bypass surgery and inflammatory bowel disease.
\end{abstract}

Case description: Herein, we described a 29-years-old man with Bowel-associated dermatosis-arthritis syndrome. He had no history of gastrointestinal surgery and inflammatory bowel disease. Distribution of the gut bacterial flora showed small intestinal bacterial overgrowth.

Discussion and Evaluation: It is rarely form as Non-intestinal bypass road and non-inflammatory bowel disease was induced by small intestinal bacteria overgrowth.

Conclusions: We concluded that Immuno-inflammatory response to overgrowth of intestinal bacterial antigen induce the clinical symptoms of bowel-associated dermatosis-arthritis syndrome.

Keywords: Dermatosis, Arthritis, Inflammatory bowel disease

\section{Background}

Bowel-associated dermatosis-arthritis syndrome (BADAS) was first described by Ely in 1980s with characteristics of fever, chills, and influenza-like symptoms with subsequent skin eruptions, myalgias, and polyarthralgias (Ely PH.1980). It is called as short-bowel syndrome since the occurrence rate among patients of jejunoileum bypass bariatric surgery is over $20 \%$ BADAS is reported to be occurred in ileoanal anastomosis, biliopancreatic diversion as well as Billroth II gastrectomy. Jorizzo described four cases (Jorizzo et al. 1983), these patients had the same clinical manifestations with shortbowel syndrome, however, they had never received any operations which mentioned above. The only common point of these patients was that they all had gastrointestinal disease and similar cases had been continuously

\footnotetext{
*Correspondence: liyisha2012@sina.com

${ }^{1}$ Department of Rheumatology and Immunology, Xiangya Hospital, Central South University, 87 Xiangya Road, Changsha, Hunan Province 410008, People's Republic of China

Full list of author information is available at the end of the article
}

reported afterwards (Delaney et al. 1989; Kemp and Gin 1990; Geary et al. 1999; Cox and Palmer 2003). Scholars believed that it was a complication of inflammatory bowel disease and put forward the concept of bowelassociated dermatosis-arthritis syndrome (BADAS) to cover the non-intestinal bypass short-bowel syndrome. A number of literatures reported that SIBO was involved in the pathogenesis of the disease. Short-bowel syndrome predisposes the patient to Small Intestine Bacterial Overgrowth (SIBO) (Goulet and Joly 2010). It has been shown that patients with Crohn's disease $(\mathrm{CD})$ have a higher risk of SIBO development (Greco et al. 2015). Herein, we described a patient with BADAS induce by small intestinal bacterial overgrowth.

\section{Case presentation}

A 29-year-old man complained of joint pain, fever, rash and intermittent diarrhea for about a year. One year ago, he had arthralgia and swelling in the ankles, knees, wrists and digital joints, together with fever $\left(>38.7^{\circ} \mathrm{C}\right)$ and erythematous nodular rashes with diameter of about $1 \mathrm{~cm}$ 

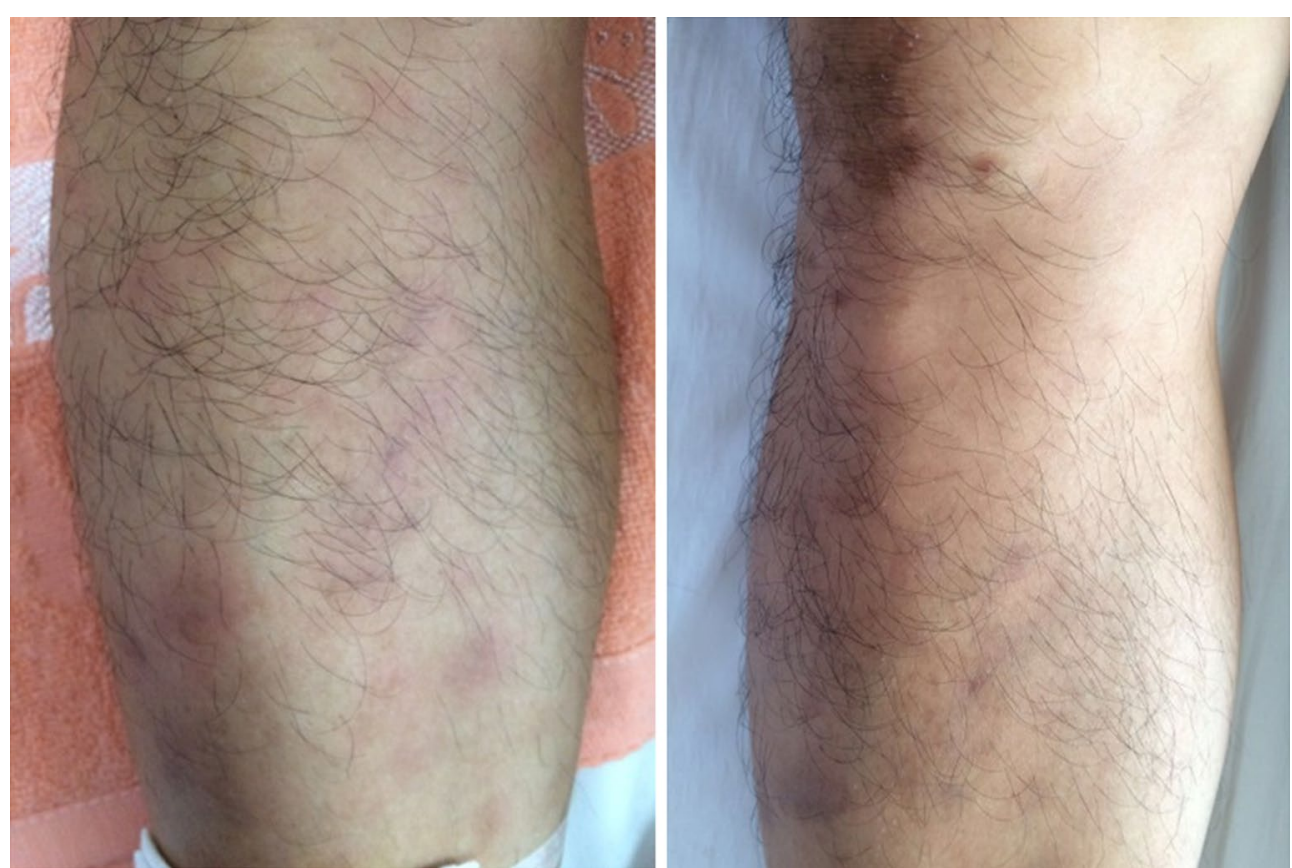

Fig. 1 The picture of red tubercular rashes on both lower limbs. Note: The patient has red tubercular rashes on both lower limbs,erythematous nodular rashes with diameter of about 3-10 $\mathrm{mm}$ and vague boundaries on his limbs

turn up on his limbs,These rashes have vague boundaries with the normal skin nearby (Fig. 1). The watery and soft stools occurred intermittently, with $3-4$ bouts a day and 4-5 days a month. He had been diagnosed with reactive arthritis. After taking non-steroidal antiinflammatory drugs (NSAIDs) such as celecoxib, arthritis, fever and rash were relieved for a short time before recurrence. He didn't undergo gastrointestinal surgery. After being admitted to our hospital, his blood cell count, urinary analysis and stool routine with occult blood test were normal. The erythrocyte sedimentation rate (ESR) $104 \mathrm{~mm} / \mathrm{h}(0-21 \mathrm{~mm} / \mathrm{h})$, C-reactive protein (CRP) $94.7 \mathrm{mg} / \mathrm{L}(0-8 \mathrm{mg} / \mathrm{l})$, interleukin-6(IL-6) $123.8 \mathrm{ng} / \mathrm{ml}$ $(0-7 \mathrm{ng} / \mathrm{ml})$ were all increased. HLA-B27 was negative. No abnormalities were found in the procalcitonin, blood culture, Multiple virus antibody, T-SPOT.TB, tumor marker, anti-nuclear antibody (ANA), anti-dsDNA antibody (AdsDNA), anti-ENA antibodies, rheumatoid factor (RF), anti-CCP, and anti-neutrophil cytoplasmic antibodies (ANCA). Electronic gastrointestinal endoscope (FUJINON EVE 400 SERIES VIDEO SYSTEM), results of abdomen $\mathrm{CT}$ and bone marrow aspiration cytology were normal. Distribution of the gut bacterial flora showed dysbacteriosis with $10 \%$ klebsiellapneumoniae, $80 \% \mathrm{E}$. coli and $10 \%$ peptostreptococcus. The result of SIBO test (hydrogen-methane breath test with lactulose as the substrate) was positive (Fig. 2). A further skin biopsy was taken from a rash on the left lower extremity and Low power microscope shows lymphocyte and neutrophile granulocyte around deep blood vessels of dermis (Fig. 3). He was diagnosed with BADAS (caused by small intestinal bacterial overgrowth). The patient was improved dramatically after treatment with doxycycline $0.2 \mathrm{~g} /$ day and methylprednisolone $40 \mathrm{mg} /$ day for a week. Glucocorticoid tapered gradually to withdrawal. The patient was followed up for 12 months without recurrent symptoms.

\section{Discussion and evaluation}

BADAS is a non-infectious neutrophilic dermatosis with prominent of features of rashes and joint pain. Typical rashes are red spots with diameter of 3-10 $\mathrm{mm}$ and vague boundaries. The rashes gradually harden in the following 1 or 2 days and turn to papulopustule with diameter of $2-4 \mathrm{~mm}$. The process of this disease could last for 2-8 days and showed as a self-limited process (Patton et al. 2009; Slater et al. 2004; Kawakami et al. 2006). The rashes are mainly distributed on the body and limbs (Jorizzo et al. 1983), and they may be featured by pruritus, pain or no subjective symptom (Slater et al. 2004). Polyarthritis may be involved in patients which had peripheral joints like IP joints and wrist joints, however, but there is no imageological change, joint destruction or deformity (Utsinger 1980). Laboratory indexes such as RF, immune globulin and uric acid are all within normal limits, however, some patients may have elevated cryoglobulin (Patton et al. 2009). In microbiological examination, both of 


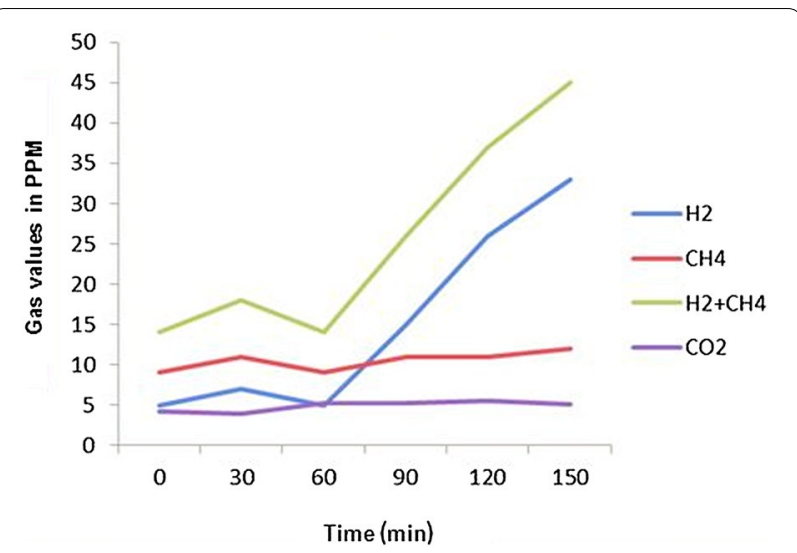

Fig. 2 The result of small intestinal bacterial overgrowth (SIBO). Note: The result of small intestinal bacterial overgrowth (SIBO) test is positive. Hydrogen-methane breath test with glucose as the substrate, after taking glucose for $1 \mathrm{~h}$, the concentration of $\mathrm{H} 2$ reached the peak value which implied the bacterial overgrowth in the ileum

blood culture and rash fester culture results are negative (Truchuelo et al. 2013). The dermal pathology of BADAS is usually the same as acute febrile neutrophilic dermatosis (SWEET) syndrome. It mainly shows infiltration of mature neutrophile granulocyte in dermis and sometimes edema of dermal papilla. It had no fibrinoid necrosis or blood vessel infarct, which is the main difference from leukocytoclastic vasculitis (Patton et al. 2009; Ashok and Kiely 2007). However, other research showed that the dermal pathology changes with the development of the disease is not an essential condition for diagnosing the BADAS (Patton et al. 2009). In the course of clinical diagnosis and treatment, BADAS also must be distinguished from extra-intestinal manifestations of inflammatory bowel disease (Adams and Eksteen 2006; Trikudanathan et al. 2012; Marineaţă et al. 2014; Brown et al. 2015).
As the cause is not clear, it is now generally accepted that it is an abnormal immune response of residual intestine after intestinal survey or abnormal intestine of inflammatory bowel disease to the bacterial overgrowth. SIBO is defined as nonpathogenic bacteria increase over $10^{5}$ cfuin $1 \mathrm{ml}$ of small intestine content. Due to the lack of specific symptoms, SIBO is often misdiagnosed. In fact, SIBO occurrence is fairly frequent. SIBO might present in more than $60 \%$ patients with abdominal pain (Siniewicz-Luzenczyk et al. 2015). In systemic sclerosis, $38 \%$ patientswith intestinal complaints were diagnosed with SIBO (Tauber et al. 2014). The formation of immune complex, access to blood and deposition in tissues and organs are crucial in the occurrence of disease which could induce various related clinical symptoms (Slater et al. 2004; Utsinger 1980; Dicken 1986; Jorizzo et al. 1984) and this theory can be indirectly proved by the curative effect of antibiotics and glucocorticoid to the disease. Glucocorticoid is as the main medicine for this disease and antibiotics (metronidazole, tetracycline and sulfonamides) are also used with different effects. Resuming the normal anatomy of intestine or curing potential gastrointestinal disease also has certain mitigative effect (Ashok and Kiely 2007).

About $20 \%$ of patients of jejunoileum bypass bariatric surgery are likely to have the symptoms of rash or joint pain (Ely 1980). Other non-bypass surgery or disease of digestive tract such as inflammatory bowel disease has had already been continuously reported, which is secondary to the BADAS (Cox and Palmer 2003; Patton et al. 2009). In our case, the clinical manifestation and dermal pathology of rashes are the same with those diseases mentioned above, however, there is no intestinal surgery, nor any evidence of inflammatory bowel disease. Only the hydrogen-methane breath test with lactulose as the substrate indicates SIBO. The disease may not merely

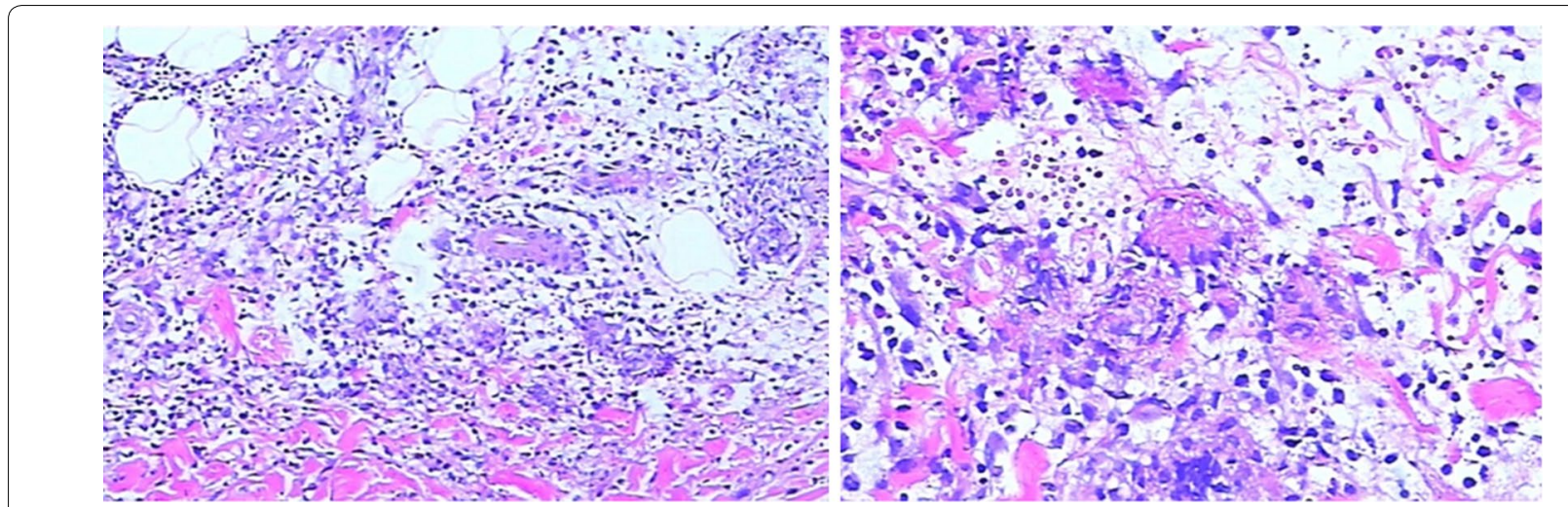

Fig. 3 The dermal pathology at rashes. Note: The dermal pathology at rashes manifests lymphocyte and neutrophile granulocyte around the deep blood vessels of dermis (rash skin of left limb, HE staining, original magnification 200-400) 
occur among patients of jejuno-ileum bypass bariatric surgery and inflammatory bowel disease as mentioned in previous literature. Immuno-inflammatory response to bacterial antigen may be caused by any factors which caused the overgrowth of intestinal bacteria, mediate formation of immune complex and hence induce the clinical symptoms of BADAS. Therefore, whether the patients had specific digestive system surgery or medical history, as organic or functional factor which may cause intestinal bacterial overgrowth should be taken into consideration during the clinical diagnosis of physician. Patient with only SIBO, non-intestinal bypass road and non-inflammatory bowel disease could also be diagnosed as BADAS.

\section{Conclusion}

In clinical practice, rheumatologists can easily recognize BADAS patients with jejunoileum bypass bariatric surgery or inflammatory bowel disease, and more attention should be paid to bacteria translocation, flora imbalance and SIBO which may also result in BADAS. Correctly understanding the factors that influence the occurrence of BADAS will help us getting to understand more about diagnosing this relatively rare disease.

\begin{abstract}
Abbreviations
BADAS: bowel-associated dermatosis-arthritis syndrome; SIBO: small intestinal bacterial overgrowth; CD: Crohn's disease; NSAIDs: non-steroidal anti-inflammatory drugs; ESR: erythrocyte sedimentation rate; CRP: C-reactive protein; IL-6: interleukin-6; HLA-B27: human leukocyte antigen B27; T-SPOT. TB: T-cell spot of TB test; AdsDNA: anti-dsDNA antibody; anti-ENA antibodies: anti-extractable nuclear antigen antibodies; RF: rheumatoid factor; anti-CCP: anti-cyclic peptide containing citrulline; ANCA: anti-neutrophil cytoplasmic antibodies; SWEET syndrome: acute febrile neutrophilic dermatosis syndrome; ANA: anti-nuclear antibody; IP: interphalangeal.
\end{abstract}

\section{Authors' contributions}

$\mathrm{HZ}$ : Management of the case and manuscript writing and correction. $\mathrm{LZ}, \mathrm{HL}$, $L D$ and YY: Management of the case and manuscript redaction and correction. WS: Cutaneous clinicopathological analysis and manuscript correction. YL: Management of the case and manuscript correction and redaction of the illustrations. XZ: Manuscript correction. All authors read and approved the final manuscript.

\section{Author details \\ 1 Department of Rheumatology and Immunology, Xiangya Hospital, Central South University, 87 Xiangya Road, Changsha, Hunan Province 410008, People's Republic of China. ${ }^{2}$ Departments of Dermatology, Xiangya Hospital, Central South University, Changsha, Hunan Province 410008, People's Republic of China.}

\section{Acknowledgements}

The authors wish to thank their colleagues of the Departments of Rheumatology and Immunology, Xiangya Hospital, Central South University.

\section{Competing interests}

HL received grants from Natural Science Foundation of Hunan Province and Hunan Provincial Science and Technology Department for Scientifi Research. The authors declare that they have no competing interests.

\section{Consent}

Written informed consent was obtained from the patient and his brother for publication of this case presentation and any accompanying image.
Received: 2 June 2016 Accepted: 6 September 2016

Published online: 13 September 2016

\section{References}

Adams DH, Eksteen B (2006) Aberrant homing of mucosal T cells and extra-intestinal manifestations of inflammatory bowel disease. Nat Rev Immunol 6(3):244-251

Ashok D, Kiely P (2007) Bowel-associated dermatosis-arthritis syndrome: a case report. J Med Case Reports 1:81

Brown C, Gibson PR, Hart A, Kaplan GG, Kachroo S, Ding Q, Hautamaki E, Fan T, Black CM, Hu X, Beusterien K (2015) Long-term outcomes of colectomy surgery among patients with ulcerative colitis. Springerplus 4:573

Cox NH, Palmer JG (2003) Bowel -associated dermatosis-arthritis syndrome associated with ileoanal pouch anastomosis, and treatment with mycophenolate. Br J Dermatol 149(6):1296-1297

Delaney TA, Clay CD, Randell PL (1989) The bowel-associated dermatosisarthritis syndrome. Australas J Dermataol 30:23-27

Dicken CH (1986) Bowel-associated dermatosis-arthritis syndrome: bowel bypass syndrome without bowel bypass. J Am Acad Dermatol 14(5 Pt 1):792-796

Ely PH (1980) The bowel bypass syndrome: a response to bacterial peptidoglycans. J Am Acad Dermatol 2:473-487

Geary RJ, Long LL, Mutasim DF (1999) Bowel bypass syndrome without bowel bypass. Cutis 63:17-20

Goulet O, Joly F (2010) Intestinal microbiota in short bowel syndrome. Gastroenterol Clin Biol 34(Suppl 1):S37-S43

Greco A, Caviglia GP, Brignolo P, Ribaldone DG, Reggiani S, Sguazzini C, Smedile A, Pellicano R, Resegotti A (2015) Glucose breath test and Crohn's disease: diagnosis of small intestinal bacterial overgrowth and evaluation of therapeutic response. Scand J Gastroenterol 50(11):1376-1381

Jorizzo JLAP, Subrt P, Hebert AA, Henry JC, Raimer SS, Dinehart SM, Reinarz JA (1983) Bowel-bypass syndrome without bowel bypass: bowel-associated dermatosis-arthritis syndrome. Arch Intern Med 143:457-461

Jorizzo JL, Schmalstieg FC, Dinehart SM, Daniels JC, Cavallo T, Apisarnthanarax P, Rudloff HB, Gonzalez EB (1984) Bowel-associated dermatosis-arthritis syndrome. Immune complex-mediated vessel damage and increased neutrophil migration. Arch Intern Med 144(4):738-740

Kawakami A, Saga K, Hida T, Jimbow K, Takahashi H (2006) Fulminant bowelassociated dermatosis-arthritis syndrome that clinically showed necrotizing fasciitis-like severe skin and systemic manifestations. J Eur Acad Dermatol Venereol 20(6):751-753

Kemp DR, Gin D (1990) Bowel-associated dermatosis-arthritis syndrome. Med J Aust 1(152):43-45

Marineată A, Rezuș E, Mihai C, Prelipcean CC (2014) Extra intestinal manifestations and complications in inflammatory bowel disease. Rev Med Chir Soc Med Nat lasi 118(2):279-288

Patton T, Jukic D, Juhas E (2009) Atypical histopathology in bowel-associated dermatosis-arthritis syndrome: a case report. Dermatol Online J 15(3):3

Siniewicz-Luzenczyk K, Bik-Gawin A, Zeman K, Bąk-Romaniszyn L (2015) Small intestinal bacterial overgrowth syndrome in children. PrzGastroenterol 10(1):28-32

Slater GH, Kerlin P, Georghiou PR, Fielding GA (2004) Bowelassociated dermatosis-arthritis syndrome after biliopancreatic diversion. Obes Surg 14:133-135

Tauber M, Avouac J, Benahmed A (2014) Prevalence and predictors of small intestinal bacterial overgrowth in systemic sclerosis patients with gastrointestinal symptoms. Clin Exp Rheumatol 32(6):S82-S87

Trikudanathan G, Venkatesh PG, Navaneethan U (2012) Diagnosis and therapeutic management of extra-intestinal manifestations of inflammatory bowel disease. Drugs 72(18):2333-2349

Truchuelo MT, Alcántara J, Vano-Galván S, Jaén P, Moreno C (2013) Bowel-associated dermatosis-arthritis syndrome: another cutaneous manifestation of inflammatory intestinal disease. Int J Dermatol 52(12):1596-1598

Utsinger PD (1980) Systemic immune complex disease following intestinal bypass surgery: bypass disease. J Am Acad Dermatol 2(6):488-495 